Luminescence study of transition metal ions in natural magmatic and metamorphic yellow sapphires

This article has been downloaded from IOPscience. Please scroll down to see the full text article.

2010 IOP Conf. Ser.: Mater. Sci. Eng. 15012086

(http://iopscience.iop.org/1757-899X/15/1/012086)

View the table of contents for this issue, or go to the journal homepage for more

Download details:

IP Address: 149.132.100.92

The article was downloaded on 13/01/2011 at 17:31

Please note that terms and conditions apply. 


\title{
Luminescence study of transition metal ions in natural magmatic and metamorphic yellow sapphires
}

\author{
V Palanza ${ }^{1}$, A Galli ${ }^{1}$, R Lorenzi ${ }^{1}$, F Moretti ${ }^{1}$, M C Mozzati ${ }^{2}$, A Paleari ${ }^{1}$ and G \\ Spinolo ${ }^{1}$ \\ ${ }^{1}$ Department of Materials Science, University of Milano-Bicocca, via Cozzi 53 \\ Milano, I-20125, Italy \\ ${ }^{2}$ Department of Physics “Alessandro Volta”, University of Pavia, via Bassi 6, Pavia, I- \\ 27100 , Italy \\ E-mail: giorgio.spinolo@mater.unimib.it
}

\begin{abstract}
Optical absorption and luminescence spectra of yellow corundum have been analyzed, both in magmatic and metamorphic materials, looking at the role of localized electronic transitions of transition metal ions at substituted Al sites. By the aid of energy dispersed x-ray fluorescence (EDXRF) elemental analysis and electron paramagnetic resonance (EPR) measurements, the results confirm that $\mathrm{Fe}^{3+}$ is the dominant impurity ion. However, the results also evidence that $\mathrm{Cr}^{3+}$ and $\mathrm{Ti}^{3+}$ contribute in determining the optical absorption and emission properties of this variety of gem-quality corundum, as we have recently found in Type 1 blue sapphires of metamorphic origin. Furthermore, preferentially but not exclusively in samples of metamorphic origin, Mn plays a role never evaluated up to now. Here we show how few ppm of Mn - below the detection limit of EDXRF, not revealed in the optical absorption spectra, but barely detected by EPR spectroscopy as $\mathrm{Mn}^{2+}$ ion - are active in photoluminescence, showing up with the characteristic emissions of $\mathrm{Mn}^{2+}, \mathrm{Mn}^{3+}$ and $\mathrm{Mn}^{4+}$.
\end{abstract}

\section{Introduction}

In a recent paper [1] we have studied the optical absorption and the photo- and radio-luminescence of Type 1 [2-3] light blue sapphire samples of metamorphic origin, also comparing them with synthetic ones. Sapphires belonging to this Type have a low iron content $\approx \approx 10^{3} \mathrm{ppm}$, all in the $\mathrm{Fe}^{3+}$ valence state) and do not show the ${ }^{5} \mathrm{E}\left(\mathrm{Fe}^{2+}\right)$ absorption band at $11500 \mathrm{~cm}^{-1}$ that is the most relevant feature of the absorption spectra of Type 2 deep blue variety of sapphires [4] of magmatic origin, much richer in iron $\left(\approx 10^{4} \mathrm{ppm}\right)$.

The combined information of absorption and emission spectroscopy (radio- and photoluminescence) allowed us to interpret the optical properties of that variety of sapphire simply on the grounds of standard crystal field theory, without making use of the somewhat debated concept of intervalence-charge-transfer IVCT $[5,6]$. In substance, we obtained strong experimental evidence of the role of $\mathrm{Cr}^{3+}$ and $\mathrm{Ti}^{3+}$ in determining the absorption and emission spectrum of such a gem.

After such a result, it appeared important to verify how far the approach held in treating Type 1 sapphires could work for corundum of different colors and, specifically, for the yellow ones and for the Type 2 blue sapphires of magmatic origin. Here we report the results of our study on yellow 
corundum, both magmatic and metamorphic, in which iron is present in concentrations comparable to that of Type 2 and Type 1 blue sapphires, respectively, but entirely in the $\mathrm{Fe}^{3+}$ oxidation state. As a consequence of the analytical, optical and electron paramagnetic resonance (EPR) data shown here, the early interpretation of the absorption spectra of yellow corundum, proposed few decades ago [4,79], has been updated.

In the following, we present new data that clarify that the origin, either magmatic or metamorphic, is relevant also for yellow corundum, specifically regarding iron concentration and emission phenomenology. We also show that, even though the optical absorption is largely due to $\mathrm{Fe}^{3+}$, contributions from $\mathrm{Cr}^{3+}$ and $\mathrm{Ti}^{3+}$ ions are also detected, but with a limited impact. On the other hand, the latter ions are more active in determining the radio- and photo-luminescence spectra, whose analysis may be useful to detect the occurrence of these species, even at low concentration. Moreover, we also show that the analysis of the photoluminescence spectrum has indeed allowed us in the present work the first identification of the occurrence of three valence states of $\mathrm{Mn}$ in natural corundum (confirmed by EPR data as regards $\mathrm{Mn}^{2+}$ species) even though in concentration below the detection limit of EDXRF, optical absorption and radioluminescence. Finally, the present work evidences once more the importance of matching data coming from different techniques for building a reliable description of the impurity related properties of a crystal.

\section{Experimental}

The samples, all natural, were platelets $5 \times 5 \mathrm{~mm}$ wide and 0.5 to $3 \mathrm{~mm}$ thick, according to the range of absorption coefficient to be explored. The information on provenance, geological origin and impurity concentration (the latter evaluated by EDXRF in ppm) of the samples studied, are shown in Table 1. We examined three different points for each sample. Table 1 reports the calculated mean values of the concentration of impurity ions and the standard deviation which gives an indication of the homogeneity extent of the distribution of metal ions in the samples. Other details of EDXRF measurements and data analysis are described in [10]. In the Table we indicate $<20$ (taking into account the detection limit of $\approx 20 \mathrm{ppm}$, for $\mathrm{Mn}$ and $\mathrm{Cr}$ ) when in the EDXRF spectrum the signal is hardly distinguishable from the noise, but there is however evidence of the occurrence of the metal species from other experiments (specifically luminescence).

Table 1. List of the investigated samples of yellow corundum, with indication of the geographical origin of and concentration of metal impurities (ppm in weight) obtained by EDXRF data.

\begin{tabular}{lccccccc}
\hline $\begin{array}{c}\text { Sample } \\
\text { Type }\end{array}$ & Provenance & $\mathrm{Ti}$ & $\mathrm{V}$ & $\mathrm{Cr}$ & $\mathrm{Mn}$ & $\mathrm{Fe}$ & $\mathrm{Ga}$ \\
\hline $\mathbf{Z 1 3}$-magm & Madagascar & $315 \pm 30$ & $15 \pm 2$ & $60 \pm 5$ & - & $10800 \pm 1000$ & $2690 \pm 270$ \\
$\mathbf{Z 1 4}$-magm & Unknown & $595 \pm 50$ & $15 \pm 2$ & $120 \pm 10$ & - & $13900 \pm 1400$ & $1485 \pm 150$ \\
Z15-magm & Unknown & $400 \pm 40$ & $15 \pm 2$ & $55 \pm 5$ & - & $10000 \pm 1000$ & $670 \pm 50$ \\
Z78-meta & Sri-Lanka & $360 \pm 28$ & $18 \pm 4$ & $33 \pm 19$ & $<20$ & $735 \pm 10$ & $477 \pm 45$ \\
Z17-meta & Sri-Lanka & $606 \pm 26$ & $21 \pm 4$ & $<20$ & $<20$ & $1832 \pm 10$ & $251 \pm 30$ \\
Z55-meta & Sri-Lanka & $210 \pm 24$ & $18 \pm 5$ & $<20$ & $<20$ & $620 \pm 80$ & $635 \pm 230$ \\
Z2-meta blue & Sri-Lanka & $850 \pm 80$ & $25 \pm 2$ & $25 \pm 2$ & $<20$ & $1230 \pm 120$ & $1410 \pm 150$ \\
\hline
\end{tabular}

Light-emission properties of the impurity species were investigated both by means of radioluminescence (RL) and photoluminescence (PL) data collected at $300 \mathrm{~K}$ or, when necessary, at $20 \mathrm{~K}$. RL measurements were performed on a custom apparatus comprising a X-ray tube $(20 \mathrm{kV}$ of accelerating potential, $5 \mathrm{~mA}$ of electron current, $\mathrm{W}$ target) as excitation source and a Charge Coupled Device (CCD) detector operating in the $9000-40000 \mathrm{~cm}^{-1}$ spectral range. The average time of X-ray exposition during RL measurement was about $30 \mathrm{~s}$, the total dose being about $1 \mathrm{~Gy}$. The comparison 
between absorption spectra recorded before and after the RL measurement did not reveal any detectable modification caused by X-ray irradiation.

Photoluminescence measurements were performed by exciting at two different wavelengths with polarized excitation by using the $488 \mathrm{~nm}$ Argon ion laser line and the fourth harmonic of a Nd:YAG laser at $266 \mathrm{~nm}$. The emission signal was analyzed by a spectrometer equipped with a 300 grooves $/ \mathrm{mm}$ grating and a CCD detector, with a final spectral resolution of about $0.36 \mathrm{~nm}$.

EPR experiments were conducted using a spectrometer in X-band $(9.4 \mathrm{GHz})$ at $300 \mathrm{~K}, 18 \mathrm{~mW}$ of microwave power, $0.2 \mathrm{mT}$ of modulation field, in condition of absence of saturation effects, at magnetic field ranging from $5 \mathrm{mT}$ to $0.8 \mathrm{~T}$. Manganese resonances were looked for both rotating the crystal around the optical axis and perpendicularly to it.

\section{Results and Discussion}

\subsection{Optical Absorption}

All the magmatic samples within the investigated set (samples Z13, Z14 and Z15) were measured both at $300 \mathrm{~K}$ and at $20 \mathrm{~K}$. In figures $1 \mathrm{a}$ and $1 \mathrm{~b}$ we show the polarized light absorption spectra of Z14 sample that is quite representative for all the magmatic samples analyzed in this work.
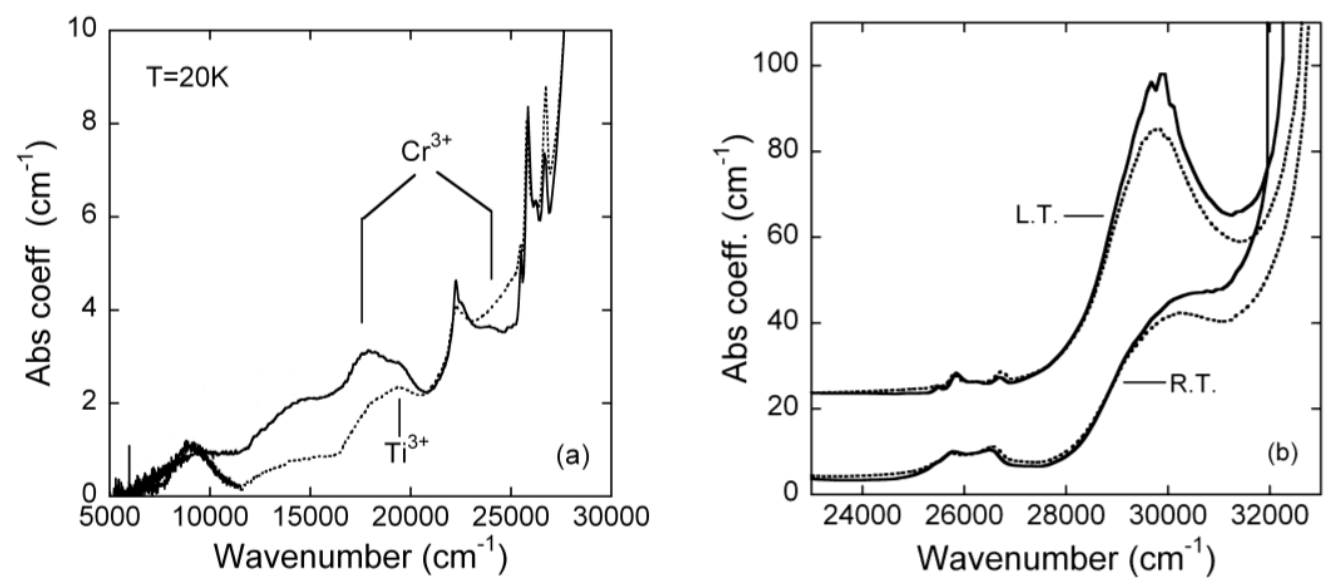

Figure 1. Absorption spectra of sample Z14. (a) Low temperature spectra in the 5000 to $30000 \mathrm{~cm}^{-1}$ interval of Z14 for $\mathrm{E} \perp \mathrm{c}$ (full line) and Ellc (dotted line) (b) Room and low temperature $(20 \mathrm{~K}), \mathrm{E} \perp \mathrm{c}$ (full line) and Ellc (dotted line) absorption spectra of Z14. Low temperature spectra are shifted upwards of $20 \mathrm{~cm}^{-1}$ for clarity.

The weak and broad bands at 9500 and $14500 \mathrm{~cm}^{-1}$ have already been observed since long [7,9] and there is no debate in attributing them to the ${ }^{4} \mathrm{~T}_{1}(\mathrm{G})$ and ${ }^{4} \mathrm{~T}_{2}(\mathrm{G})$ levels of $\mathrm{Fe}^{3+}$. The band peaking at $\approx 17500 \mathrm{~cm}^{-1}$ was first attributed to a split component of the ${ }^{4} \mathrm{~T}_{2}(\mathrm{G})$ state [7] and, later, to pair ${ }^{4} \mathrm{~T}_{1}(\mathrm{G})+$ ${ }^{4} \mathrm{~T}_{1}(\mathrm{G})$ ] transitions occurring simultaneously in a couple of adjacent $\mathrm{Fe}^{3+}$ ions [9]. Kiefert and Schmetzer [4] proposed to attribute the band to $\mathrm{Ti}^{3+}$ while in ref. [8] Krebs and Maisch gave reasons in favour of $\mathrm{Cr}^{3+}$. We propose that the absorption between 17000 and $21000 \mathrm{~cm}^{-1}$ is due to the sum of contributions from both the ${ }^{4} \mathrm{~T}_{2}$ spin-allowed transition of $\mathrm{Cr}^{3+}$ and the ${ }^{2} \mathrm{E}$ transition of $\mathrm{Ti}^{3+}$, in agreement with the interpretation given on Type 1 sapphires in ref. [1] and confirmed by the radioand photo-luminescence measurements shown in Figures 3-5. Other features in the spectra of figures $1 \mathrm{a}$ and $1 \mathrm{~b}$ are due to $\mathrm{Fe}^{3+}$ and well interpreted in the frame of the $d^{5}$ Tanabe - Sugano diagrams: the narrow peaks at about 22000 and at $26000-27000 \mathrm{~cm}^{-1}$ are due to the ${ }^{4} \mathrm{~A}_{1},{ }^{4} \mathrm{E}(\mathrm{G})$ and ${ }^{4} \mathrm{~T}_{2}(\mathrm{D})$ and ${ }^{4} \mathrm{E}$ (D) spin-forbidden transitions of $\mathrm{Fe}^{3+}$, respectively [8]. At about $24500 \mathrm{~cm}^{-1}$, the spectra show a bump that should be attributed to the ${ }^{4} \mathrm{~T}_{1}$ spin-allowed transition of $\mathrm{Cr}^{3+}$, submerged between the above mentioned ${ }^{4} \mathrm{~A}_{1},{ }^{4} \mathrm{E}(\mathrm{G})$ and ${ }^{4} \mathrm{~T}_{2}(\mathrm{D})$ and ${ }^{4} \mathrm{E}(\mathrm{D})$ spin-forbidden transitions of $\mathrm{Fe}^{3+}$. The strong band at about $29800 \mathrm{~cm}^{-1}$, whose intensity increases at low temperatures and with the concentration of $\mathrm{Fe}^{3+}$, 
has been attributed either to an exchange enhanced ${ }^{4} \mathrm{~T}_{1}(\mathrm{P})$ or to the simultaneous excitation of a ${ }^{4} \mathrm{~T}_{2}(\mathrm{G})$ transition in an exchange coupled pair of ions [8]. Both processes are undoubtedly outside the crystal field theory frame, since their effects are not detected in analogous $\mathrm{Fe}^{3+}$ spectra, such as those in berylaquamarine [11] or in aqueous solutions [12]. In the latter systems, two $\mathrm{Fe}^{3+}$ ions cannot occupy nextnearest neighbor positions, since they are farther away from each other and their possible exchange interaction is consequently extremely weak. We conclude the comments on figures $1 \mathrm{a}$ and $1 \mathrm{~b}$ observing that the growth conditions of yellow corundums were doubtless highly oxidizing, since there is no evidence of $\mathrm{Fe}^{2+}$ nor $\mathrm{Cr}^{2+}$.

In figure 2 we show the absorption spectrum of a typical yellow metamorphic corundum from Sri Lanka, very similar to that shown in ref. [7].

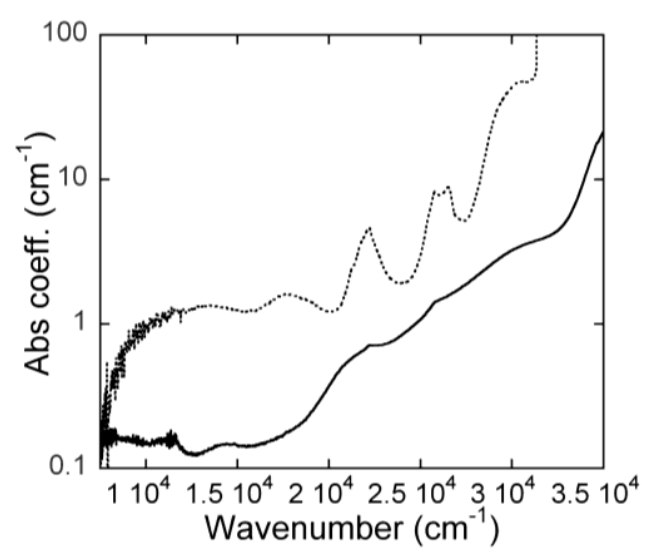

Figure 2. Room temperature absorption spectra of magmatic Z14 $\mathrm{E} \perp \mathrm{c}$ (dashed line) and metamorphic $\mathrm{Z78} \mathrm{E} \perp \mathrm{c}$ (full line).

There is little to add to the comments we made in our previous work on the spectra of magmatic samples (whose spectrum is shown again, for comparison), except considering that, in the case of metamorphic origin, the intensity of the bands related to the presence of $\mathrm{Fe}^{3+}$ (inclusive of the "exchange enhanced" $\left.{ }^{4} \mathrm{~T}_{1}(\mathrm{P})\right)$ and $\mathrm{Cr}^{3+}$ is much lower, coherent with the concentration data shown in Table 1. Under these very weak absorption bands one may notice a broad and unstructured absorption from 20000 to $32000 \mathrm{~cm}^{-1}$ attributed to color centers related to defects originated from ambient dose[7]. Such a broad feature cannot be reliably submitted to a Gaussian analysis but the absorption due to the spin allowed transitions of $\mathrm{Ti}^{3+}, \mathrm{Mn}^{3+}$ and $\mathrm{Mn}^{4+}$, whose presence is proved by photoluminescence spectra, should give a contribution to the optical absorption in that energy region.

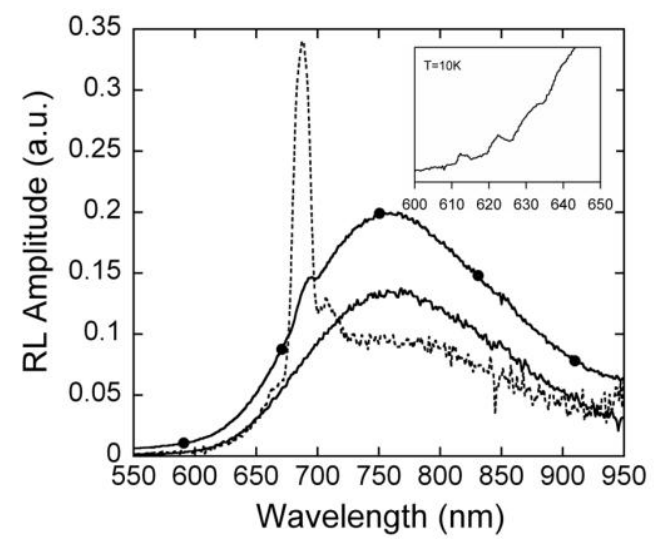

Figure 3. Room temperature radioluminescence spectra of Z13 (dotted line), Z55 (black circles) and Z78 (full line).In the inset, greater detail is given for the low energy tail of $\mathrm{Ti}^{3+}$ emission at $10 \mathrm{~K}$.

\subsection{Radio- and Photo- luminescence}

Radio-luminescence has been recently found by us to be quite useful to identify the presence of small amounts of transition metal species in crystals [1]. In figure 3 we show the most representative radio- 
luminescence spectra we obtained within the investigated sample set, specifically those collected on magmatic Z13 and on metamorphic Z78 and Z55 samples.

In Z13 we observe both the sharp $\mathrm{Cr}^{3+}$ and the broad $\mathrm{Ti}^{3+}$ emissions at 14300 and $13000 \mathrm{~cm}^{-1}$, respectively. In $\mathrm{Z78}$, the $\mathrm{Cr}^{3+}$ emission is not detectable while in $\mathrm{Z55}$ is detectable but very weak. From these RL data, in particular from Z13 spectrum, it appears that $\mathrm{Cr}^{3+}$ is more efficient than the five times more abundant $\mathrm{Ti}^{3+}$ (see Table 1) in capturing the ionized carriers, the first step of the RL process. In Z78 and in Z55 there is a similar amount of $\mathrm{Ti}^{3+}$ but much less $\mathrm{Cr}^{3+}$. In the inset of figure 3 we also show the fingerprint of the $\mathrm{Ti}^{3+}$ emission, from the zero, one and two phonon states of ${ }^{2} \mathrm{E}$ level to the zero phonon state of ${ }^{2} \mathrm{~T}_{2}$ observed at low temperatures and interpreted by Gächter and Koningstein [13]. No quantitative analysis about ion concentration can instead be done from RL data in view of the non homogeneous distribution of emitting sites and the competition in capturing free carriers by different ions.

The results of PL experiments are reported in figure 4. The magmatic Z13 sample shows, as expected, a strong and sharp emission from the ${ }^{2} \mathrm{E}$ state of $\mathrm{Cr}^{3+}$, accompanied by phonon sidebands. No evident $\mathrm{Ti}^{3+}$ emission is instead detected, indicating that the $488 \mathrm{~nm}$ excited $\mathrm{Cr}^{3+}$ radiative decay is quite more efficient than $\mathrm{Ti}^{3+}$ light emission at the same excitation energy, which should fall within the absorption spectra of both ions.

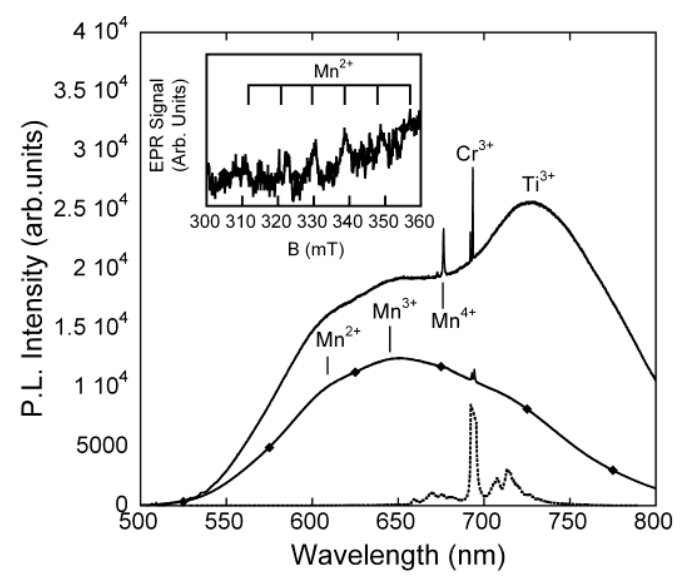

Figure 4. Room temperature photoluminescence spectra of Z13 (dotted line), and $\mathrm{Z78}$ (circles); $77 \mathrm{~K} \mathrm{PL}$ spectrum of Z78 (full line). In the inset EPR spectra of sample Z78.

The Z78 spectrum is instead quite surprising and richer than expected because, besides the $\mathrm{Ti}^{3+}$ broad emission band and the sharp ${ }^{2} \mathrm{E}$ doublet of $\mathrm{Cr}^{3+}$, other emission bands and a sharp doublet appear, better resolved at low temperature. No trace of these features is observed in RL because of the high competitive efficiency of the largely abundant $\mathrm{Ti}^{3+}$ in capturing X-ray produced free carriers. The latter PL bands and doublet show spectral features typical of light emission ascribable to Mn, as we discuss just below. The sites responsible for these emissions show a high PL efficiency - as indeed in the case of Mn sites in several hosts - since the concentration of the related species is surely very low. In fact, no potential candidate (including $\mathrm{Mn}$ ) is reliably evidenced above the detection limit of EDXRF and optical absorption. On the other hand, the confirmation of the occurrence of Mn species comes from EPR spectra that show weak resonances (inset of figure 4) characterized by hyperfine structures composed by sextets of lines spaced by about $9 \mathrm{mT}$, as expected from paramagnetic hyperfine interactions of the electronic configuration of $\mathrm{Mn}^{2+}$ ions with the $I=5 / 2$ nuclear spin of the $100 \%$ abundant ${ }^{55} \mathrm{Mn}[14]$.

The concentration of $\mathrm{Mn}^{2+}$ ions, barely detectable and just above the noise in our experiment, is hardy quantifiable and should be of few ppm at most. The concentration of $\mathrm{Mn}^{4+}$ sites turns out even lower since it is below the detection limit of EPR measurements. No indication can be given on $\mathrm{Mn}^{3+}$ ions that are EPR silent in the X-band microwave energy region of our instrumentation [15]. The attribution of the observed PL emissions to Mn species is indeed consistent, as anticipated above, with the known spectral features of Mn centers in other hosts. The attribution of the doublet at $672-676$ 
$\mathrm{nm}$ to the ${ }^{2} \mathrm{E} \rightarrow{ }^{4} \mathrm{~A}_{2}$ transition of $\mathrm{Mn}^{4+}$ (a $d^{3}$ ion) is quite straightforward [16]. Furthermore, $\mathrm{Mn}^{2+}$ emits at around $620 \mathrm{~nm}$ in many minerals [17] and $\mathrm{Mn}^{3+}$ emits at around $650 \mathrm{~nm}$ in several garnets [18].

The analysis of PL spectra within the investigated set of samples shows that the presence of Mn in yellow corundum is preferential in material of metamorphic origin. However it is not an exclusive feature of metamorphic materials since we have found it also in a blue-yellow mixed color magmatic sample showing the $\mathrm{Mn}^{4+}{ }^{2} \mathrm{E} \rightarrow{ }^{4} \mathrm{~A}_{2}$ doublet as the characterizing feature of the PL spectrum [19].

In view of the rich luminescence phenomenology we encountered and of the fact that luminescence is often used as a characterization test in the current practice of gemological analysis (either excited at $254 \mathrm{~nm}$ or $366 \mathrm{~nm}$ ), we excited some of our samples by the fourth harmonic of a Nd:YAG laser at 266 $\mathrm{nm}\left(37593 \mathrm{~cm}^{-1}\right)$.

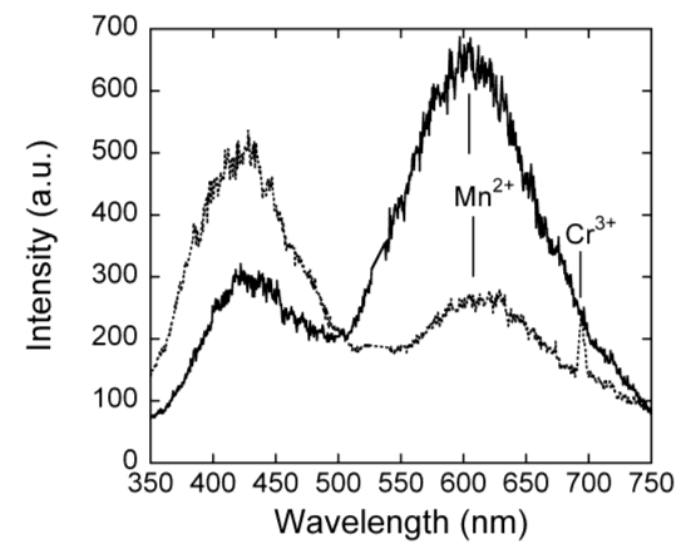

Figure 5. Room temperature photoluminescence spectra of $\mathrm{Z} 2$ (dotted line) and Z78 (full line).

In figure 5 we show the emissions of Z2 and Z78 under such an excitation. In Z78 we observe two emission peaks, one centered at $\approx 425 \mathrm{~nm}$, due to $\mathrm{F}^{+}$centers [20], and the low energy one at $\approx 605 \mathrm{~nm}$ and due to $\mathrm{Mn}^{2+}$. In $\mathrm{Z} 2$ the same emissions are present, together with the narrow emission of $\mathrm{Cr}^{3+}$ at $\approx 700 \mathrm{~nm}$. On the other hand, the fourth harmonic of a Nd:YAG laser does not overlap excitation bands of $\mathrm{Mn}^{3+}, \mathrm{Mn}^{4+}$ and $\mathrm{Ti}^{3+}$. So, we may conclude that the visual "luminescence test" currently used in the professional gemmological practice may give in some cases a quite questionable characterization of the fluorescence activity of corundum gems.

\section{Conclusion}

The study of radio- and photo-luminescence of the investigated samples supports the interpretation of the optical absorption of yellow corundum in accordance with the approach we adopted in treating Type 1 blue sapphires, attributing a role in the absorption spectrum to $\mathrm{Ti}^{3+}$ and $\mathrm{Cr}^{3+}$ ions detected by EDXRF. Metamorphic samples of rather inconspicuous absorption spectrum show an emission spectrum in which $\mathrm{Cr}^{3+}, \mathrm{Ti}^{3+}$ and $\mathrm{Mn}$ (in more than one valence state) undoubtedly contribute. EPR confirms the presence of $\mathrm{Mn}$ in concentration below the detection limit of EDXRF and optical absorption techniques.

\section{Acknowledgments}

One of us (V.P.) is thankful to Regione Lombardia for a scholarship in the frame of "Progetto Ingenio". We also thank L. Prosperi of the Italian Gemological Institute for supplying most of the specimens we studied. 


\section{References}

[1] Fontana I, Le Donne A, Palanza V, Binetti S and Spinolo G 2008 J. Phys-Condens. Mat. 20 125228

[2] Schmetzer K and Kiefert L $1990 \mathrm{~J}$. Gemm. 2280

[3] Milisenda CC and Henn U 1996 J. Gemm. 25177

[4] Kiefert L and Schmetzer K 1987 J. Gemm. 20427

[5] Burns RG 1993 Mineralogical Applications of Crystal Field Theory (Cambridge: Cambridge University Press) p 127

[6] Nassau K 2001 The Physics and Chemistry of Color (New York: Wyley) p 143

[7] Lehmann G and Harder H 1970 Am. Miner. 5598

[8] Krebs JJ and Maisch WG 1971 Phys. Rev. B 4757

[9] Ferguson J and Fielding PE 1972 Aust. J. Chem. 251371

[10] Bonizzoni L, Galli A, Spinolo G, Palanza V 2009 Anal. and Bioanal. Chem. 3952021

[11] Spinolo G, Fontana I, Galli A 2007 Phys. Stat. Solidi (b) 2444660

[12] Fontana I, Lauria A and Spinolo G 2007 Phys. Stat. Solidi (b) 2444669

[13] Gächter BF and Koningstein JA 1974 J. Chem. Phys. 602003

[14] Rakhimov RR, Jackson EM, Jones DE and Loutts GB 2004 J. Appl. Phys. 955653

[15] Goldberg D P, Telser J, Krzystek J, Montalban AG, Brunel LC, Barrett AGM and Hoffman BM 1997 J. Am. Chem. Soc. 1198722

[16] Geschwind S, Kisliuk P, Klein MP, Remeika JP and Wood DL 1962 Phys. Rev. 1261684

[17] Green GR and Walker G 1985 Phys. Chem. Minerals 12271

[18] Kück S, Hartung S, Hurling S, Peterman K and Huber G 1998 Phys. Rev. B 572203

[19] Drera B, Palanza V and Spinolo G 2009 Riv. Gemm. Ital. 4115

[20] Brewer JD, Jeffries BT, and Summers GP 1980 Phys. Rev. B 224900 